\title{
Bir rüzgar enerji santralindeki rüzgar türbinlerinin yerleşimlerinden kaynaklanan güç kayıplarının hesaplanmas1
}

\author{
Melike Sultan KARASU AŞNAZ ${ }^{1, *}$, Bedri YÜKSEL ${ }^{2}$ \\ ${ }^{1}$ Balıkesir Üniversitesi Mühendislik Fakültesi, Endüstri Müh. Böl., Çağlş Kampüsü, Balıkesir. \\ ${ }^{2}$ İstanbul Gelişim Üniversitesi, Mühendislik ve Mimarllk Fakültesi, Mekatronik Müh. Böl., İstanbul.
}

Geliş Tarihi (Recived Date): 13.08.2018

Kabul Tarihi (Accepted Date): 06.10.2018

\section{Özet}

Bu çalışmanın amacı; Türkiye'de bulunan bir rüzgar enerji santralindeki mevcut rüzgar türbinlerinin birbirleriyle olan etkileşimlerinden kaynaklanan güç kayıplarının hesaplanmasıdır. Çalışmada ele alınan 29 adet 3MW'lık rüzgar türbinleri ile toplamda 87MW'lık kurulu güce sahip bir rüzgar santralinin öncelikle saha şartlarının ve rüzgar koşullarının analizi yapılmıştır. Ardından mevcut yerleşim düzenine göre her bir türbinin ve rüzgar santralinin iz etkisinden kaynaklanan kayıplarl hesaplanmıştır. Sonuç olarak, bir rüzgar türbinin mekanik dayanımını korumak için kanatlardaki yükleri azaltmak gerekliliği ve iz etkisinden kaynaklı güç kayıplarının önemli bir olgu olduğu vurgusu yapılmıştır.

Anahtar kelimeler: Rüzgar santralleri, rüzgar türbini yerleşimi, iz etkisi, mikrokonumlandirma.

\section{Calculation of wake losses due to placements of wind turbines in a windfarm}

\begin{abstract}
The purpose of this study is the calculation of power losses due to the interactions of wind turbines in a wind farm located in Turkey. To begin with, the wind farm terrain and wind conditions are analyzed in the windfarm that has 29 wind turbines of $3 M W$ and a total installed capacity of 87MW. Then, the wake losses of each wind turbine and whole wind farm are calculated based on the existing layout. As a result, it is

\footnotetext{
*Melike Sutan KARASU AŞNAZ, karasu@balikesir.edu.tr, https://orcid.org/0000-0003-4145-2524 Bedri YÜKSEL, byuksel@gelisim.edu.tr, https://orcid.org/0000-0002-8233-3129
} 
emphasized that power losses due to wake effects are an important fact, also it is necessary to reduce the loads on rotor in order to maintain the mechanical strength of wind turbines.

Keywords: Windfarm, wind turbine placement, wake effect, micro-siting.

\section{Giriş}

Rüzgar enerji santralleri (RES) projeleri hem inşaat hem de bakım açısından yüksek miktarda yatırım gerektiren projelerdir. Yatırımcıların, yüksek maliyetler karşısında risklerini düşürmek ve rüzgar gücü kullanımını artırmaya yönelmeleri adına, rüzgarla ilgili mekanik, aerodinamik, elektronik, yöneylem ve çevresel etmenler gibi konularda araştırma yapmaları teşvik edilmektedir.

Genel olarak yatay eksenli üç kanatlı rüzgar türbinlerinin verimi \%38-45 arasında değişmektedir, yani \%55-62 arasında bir güç kaybı yaşanır. Türbin verimini düşüren bu kayıplar; aerodinamik kayıplar, mekanik kayıplar ve elektriksel kayıplardır [1]. Söz konusu kayıplar hakkında akademik camiadan özellikle ilgi gören konu, türbinler arasındaki aerodinamik etkileşim sonucu türbine çarpan rüzgar hız kayıplarını en aza indirerek toplam güç üretimini en üst düzeye çıkarma çalışmalarıdır [2]. Bu önemi vurgulamak için gerçek bir RES'teki türbinlerin etkileşmeleri sonucu yaşanan güç kayıplarının boyutu bu çalışma ile vurgulanmak istenmiştir.

\section{Yöntem}

\subsection{Rüzgar enerji santrali sahast}

Bu çalışmada incelenen RES'in kurulu gücü 87 MW'tır. Sahada yirmidokuz adet 3MW'lık Danimarka menşeili Vestas V90-3.0 model rüzgar türbini kullanılmıştır.

İşletmeden temin edilen veriler çerçevesinde, bölgenin topografik özellikleri sayısal olarak modellenmiştir. Bu model hem yeryüzü şekillerinin hem de yükselti farklarının rüzgar akışına etkisini inceleme firsatı sunmaktadır. RES sahasının eşyükselti haritası Şekil 1'de verilmiştir.

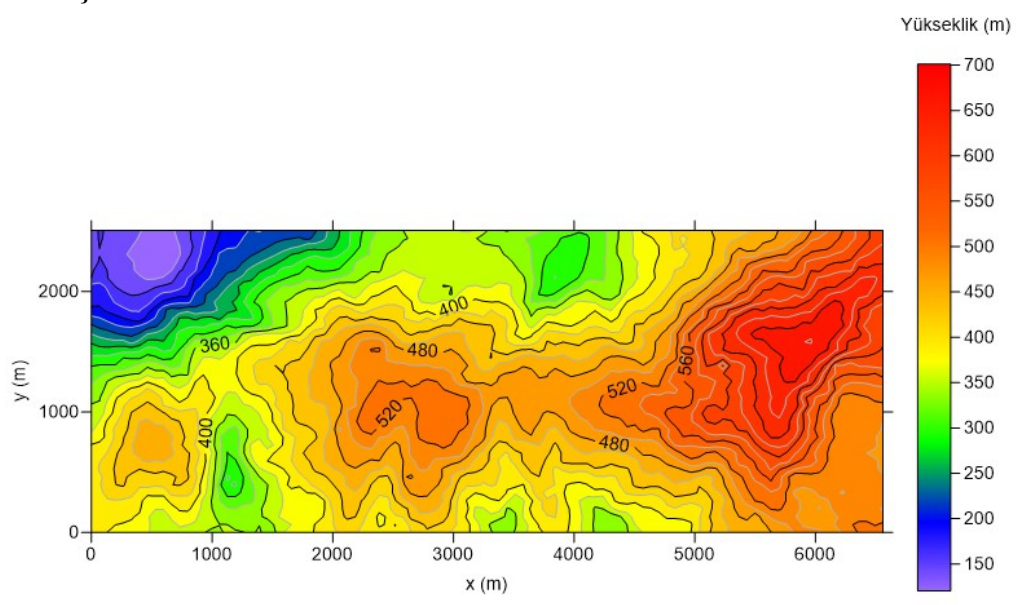

Şekil 1. RES sahasını kaplayan bölgenin eşyükselti haritası. 
Şekil 2'de ise kırmızı çizgi saha sınırlarını, kırmızı noktalar sahadaki mevcut 29 adet rüzgar türbininin yerleşim düzenini eşyükselti haritası ile birlikte göstermektedir.

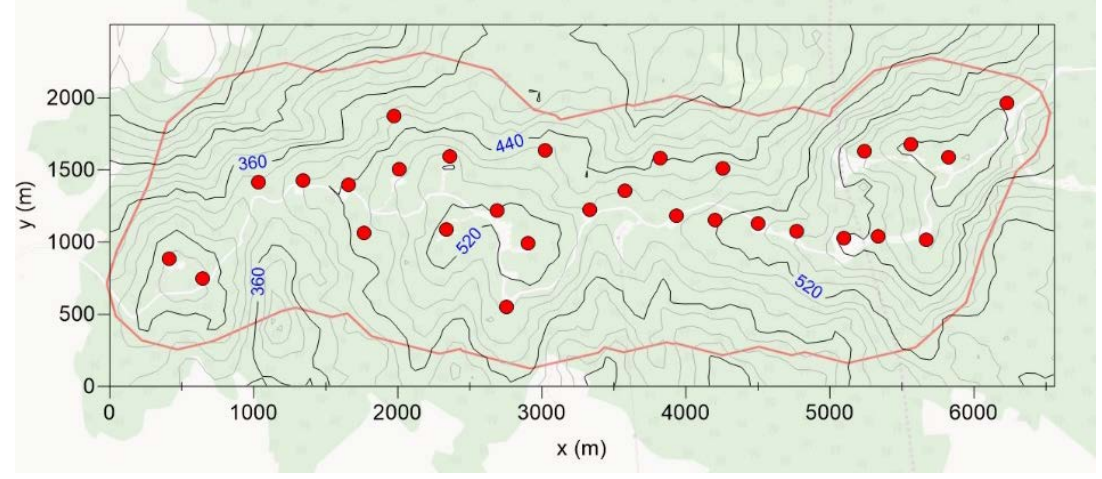

Şekil 2. Mevcut santral düzeni ve saha sınırları.

\subsection{Sahada kullanılan rüzgar türbininin özellikleri}

İncelenen RES'te kullanılan tek tip rüzgar türbini vardır; 29 adet Vestas marka 3 MW'lık V90-3.0. Kullanılan türbinin rotor çap1 $90 \mathrm{~m}$, süpürme alanı $6362 \mathrm{~m}^{2}$ ve hub yüksekliği $80 \mathrm{~m}$ 'dir. Devreye girme hızı $4 \mathrm{~m} / \mathrm{s}$ iken türbin nominal çalışmaya $15 \mathrm{~m} / \mathrm{s}$ ile başlamaktadır, $25 \mathrm{~m} / \mathrm{s}$ 'de ise türbin devreden çıkmaktadır. Rüzgar hızlarına karşılık gelen türbine ait güç üretim eğrisi ve kapasite faktörleri grafiği Şekil 3’te gösterilmektedir.

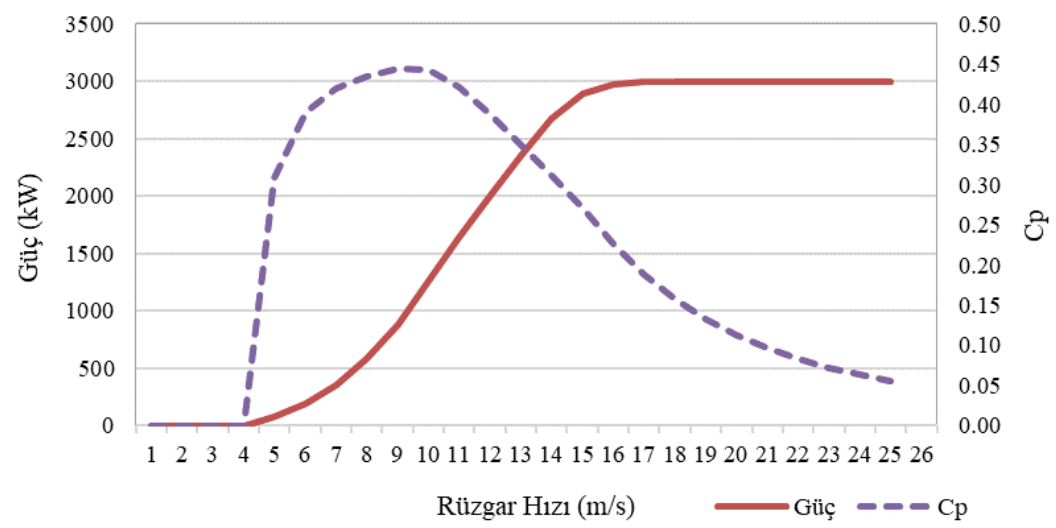

Şekil 3. Vestas V90-3.0 model türbinin güç ve kapasite faktörü eğrisi.

\section{Materyal ve yöntem}

\subsection{Rüzgar veri analizi}

Saha içerisinde yer alan ölçüm direğinden $80 \mathrm{~m}, 65 \mathrm{~m}, 50 \mathrm{~m}$ olmak üzere toplam üç yükseklik seviyesinden rüzgar hız ve yön ölçümleri alınmıştır. Bir yıllık süre içerisinde, onar dakikalık aralıklarla kayıt yapılan rüzgar hızları ve yönlerine ait verilerden oluşturulan özet veriler [3] Tablo 1’de görülmektedir.

$80 \mathrm{~m}$ yükseklik ölçümlerine göre sahanın ortalama rüzgar hızı $7,54 \mathrm{~m} / \mathrm{s}$ 'dir. Ölçüm yapılan zaman diliminde en yüksek hız $28,25 \mathrm{~m} / \mathrm{s}$ olarak ölçülmüştür. $2,5 \mathrm{~m} / \mathrm{s}$ ve 
altındaki rüzgar hızları sakin rüzgar olarak tanımlanmış ve zamanın $\% 6,45$ 'inde bu değerlerde esmiştir.

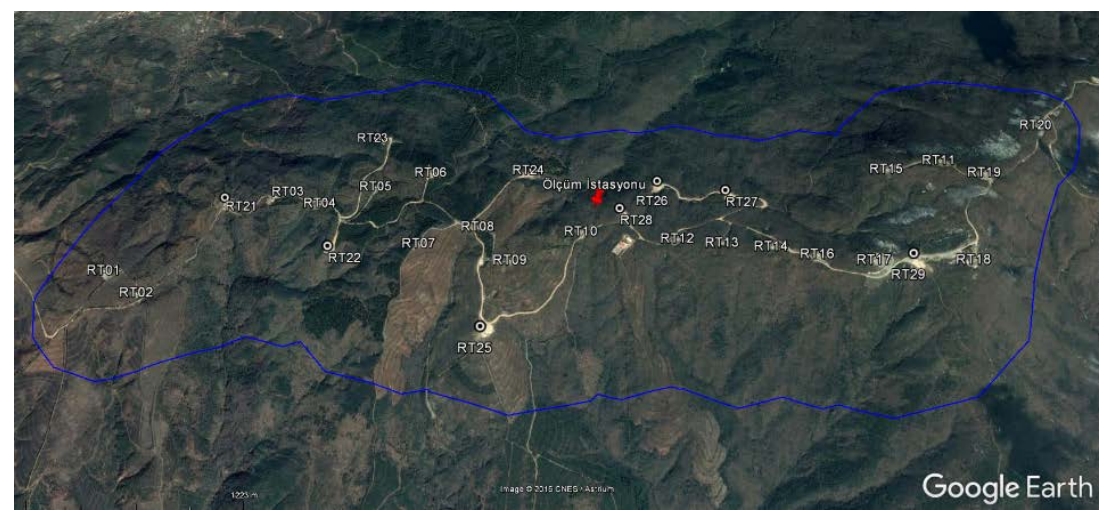

Şekil 4. Santral saha sınırları içindeki türbinler ve ölçüm istasyonu.

Santralin hakim rüzgar yönü \%40,4 esme sıklığı ile 22,5\%'den gelen kuzey- kuzeydoğu ve $\% 18,37$ esme sıklığ Ölçümlerden rüzgar hızının dağılımı da incelenmiş ve weibull parametreleri bulunmuştur. $80 \mathrm{~m}$ yükseklik verilerine göre weibull şekil parametresi 1,17 iken; ölçek parametresi ise $8,68 \mathrm{~m} / \mathrm{s}$ olarak hesaplanmıştır. Sahanın ortalama enerji yoğunluğu ise birim metrekare başına $612 \mathrm{~W}$ olarak bulunmuştur.

Tablo 1. Ölçüm istasyonundan alınan rüzgar verileri.

\begin{tabular}{|l|c|c|c|}
\hline & $80 \mathrm{~m}$. sensörü & $65 \mathrm{~m}$. sensörü & $50 \mathrm{~m}$. sensörü \\
\hline Ortalama Rüzgar Hızı (m/s) & 7,54 & 7,33 & 7,07 \\
\hline Medyan Rüzgar Hızı (m/s) & 7,02 & 6,81 & 6.58 \\
\hline Maks. Rüzgar Hızı (m/s) & 28,25 & 27,50 & 25,91 \\
\hline Rüzgar Esme Yönü ( $\left.{ }^{\circ}\right)$ & $\begin{array}{c}\% 40,4-22,5^{\circ} \\
\% 18,37-157,5^{\circ}\end{array}$ & $\begin{array}{c}\% 39,04-22,5^{\circ} \\
\% 18,49-157,5^{\circ}\end{array}$ & $\begin{array}{c}\% 39,54-22,5^{\circ} \\
\% 18,60-157,5^{\circ}\end{array}$ \\
\hline Weibull k & 1,17 & 1,17 & 1,18 \\
\hline Weibull c (m/s) & 8,68 & 8,59 & 8,34 \\
\hline $\begin{array}{l}\text { Ort. Enerji Yoğunluğu } \\
\left(W / m^{2}\right)\end{array}$ & 612 & 563 & 503 \\
\hline Sakin Rüzgar Sıklığı (\%) & 6,45 & 6,45 & 6.39 \\
\hline
\end{tabular}

$22,5^{\circ}$ aralıklarla oluşturulan 16 sektöre göre rüzgar esme frekansları hesaplanmıştır. Şekil 5'te saha sınırları içerisindeki mevcut türbin yerleşim düzeni ile birlikte ölçüm istasyonu noktasındaki rüzgar gülü de görülmektedir. 


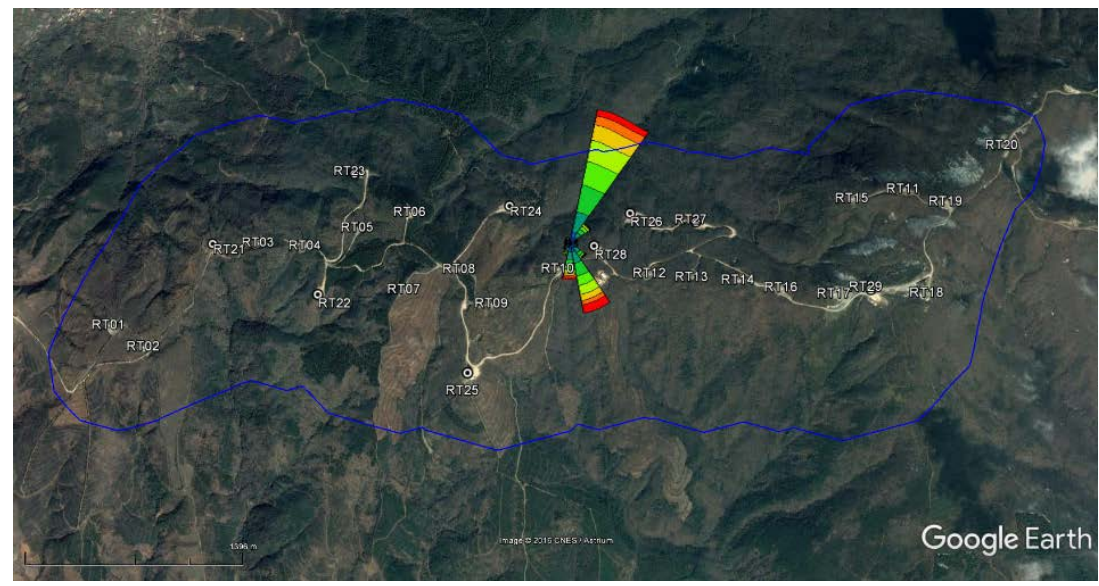

Şekil 5. Rüzgar gülü ve saha sınırları içindeki mevcut yerleşim düzeni.

Her bir sektörü $22,5^{\circ}$ 'lik 16 eş bölgeye ayrılan ve rüzgarın esme yönlerini gösteren rüzgar gülleri Şekil 6' da verilmiştir. Bu şekil, RES sahasında aylara göre rüzgarın esme yönünün değişimini göstermektedir. Ocak, Şubat ve Mart aylarında güneyden esen rüzgarlar ve Mayıs ayından itibarense kuzey yönünden esme sıklığı artan rüzgarlar dikkat çekmektedir.
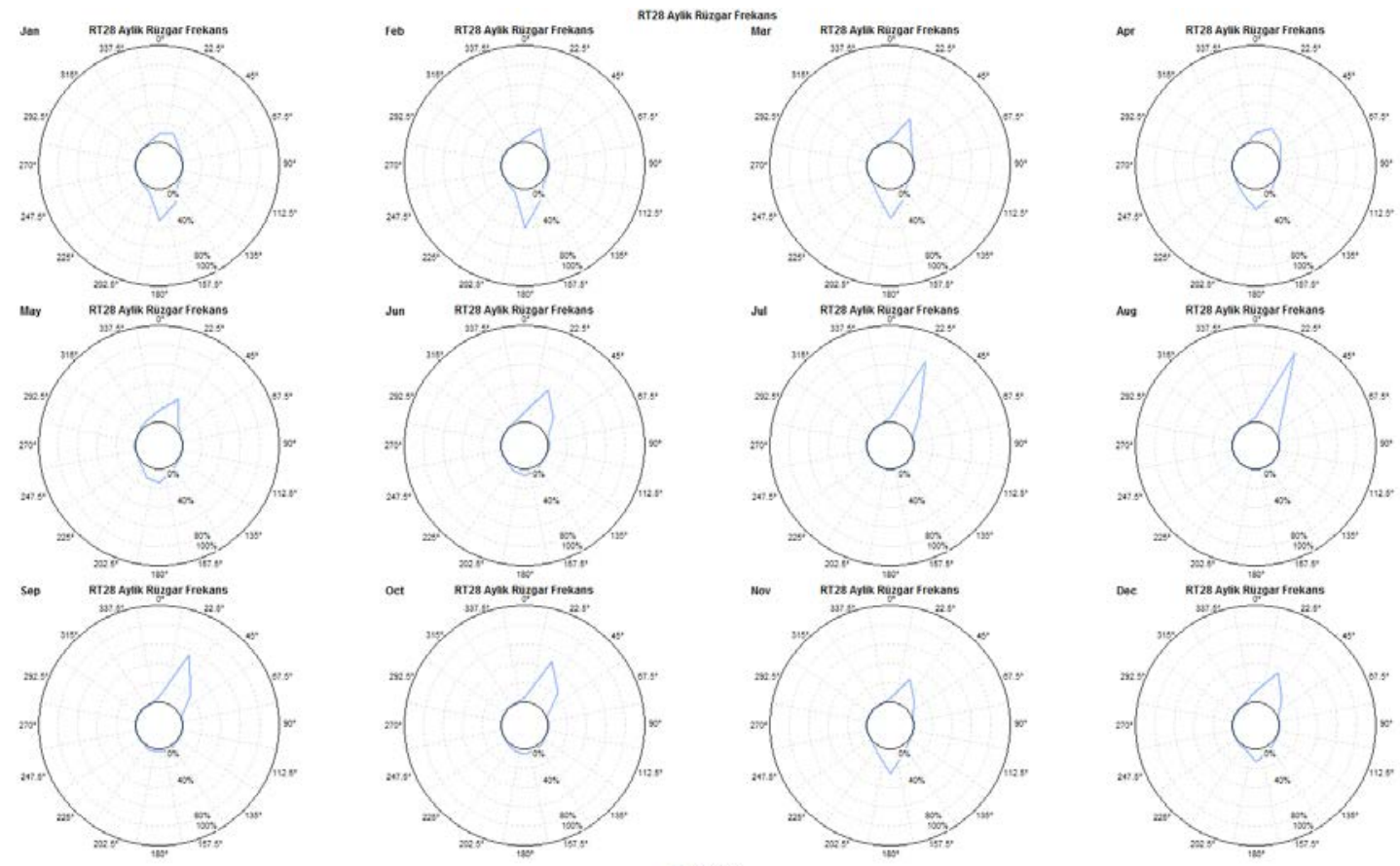

Şekil 6. Aylara göre rüzgar esme sıklığı ve yön değişimi.

Kullanılmakta olan V90-3.0 model türbinlerin bu saha koşularındaki kapasite faktörleri, yönlere göre hesaplanmış ve 16 farklı kapasite faktör $\left(C_{p}\right)$ değerleri bulunmuştur, grafiği Şekil 7’de görülmektedir. 


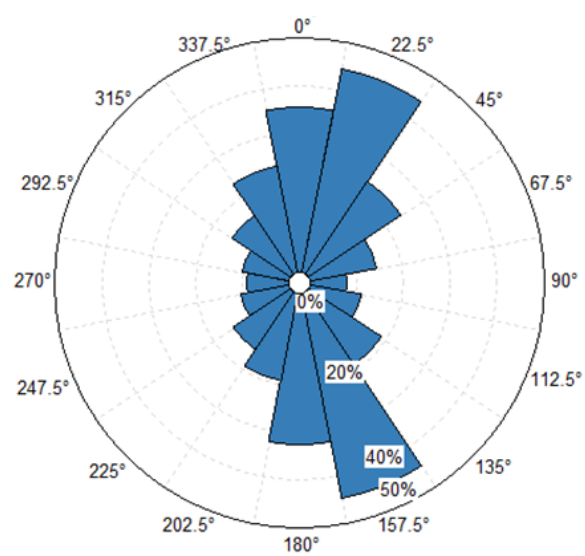

Şekil 7. Yönlere göre V90-3.0 model türbininin $C_{p}$ değerleri.

Rüzgar türbinin performans katsayısı olarak da ifade edilen kapasite faktörü oranları; rüzgardan elde edilen gücün, rüzgar gücüne oranı ile bulunmuştur. Sistemin verimlilik ölçütü olan bu hesaplama yapılırken sahada hiçbir kayıp olmadığı varsayılmıştır [4].

\subsection{Güç hesaplaması}

Güç hesaplamaları eşitlik (1) ve (2)'de verilmiştir. Sahada kullanılan V90-3.0 türbin modeli; 4m/s'den az ve $25 \mathrm{~m} / \mathrm{s}$ 'den fazla olan rüzgar hızlarında güç üretmezken, $15 \mathrm{~m} / \mathrm{s}$ ile $25 \mathrm{~m} / \mathrm{s}$ arasında türbinler nominal güç üretmektedirler. $4 \mathrm{~m} / \mathrm{s}$ ile $15 \mathrm{~m} / \mathrm{s}$ arasında kalan rüzgar hızlarında ise her bir türbinin 16 farklı yöne göre ortalama hızları ve kapasite faktörleri dikkate alınmaktadır. $U_{o, i}$; türbinin konumlandırıldığı yüksekliğe göre düzeltilmiş ve $\theta$ açısından esen iz etkisi kayıpları hesaplanmış, türbine çarpan rüzgarın yıllık ortalama hızını ifade etmektedir. $C_{p, i}$ ise, $\theta$ açısından esen rüzgarın ortalama hızına göre hesaplanmış kapasite faktörüdür. $\rho$, havanın yoğunluğu; $A$ türbinin süpürme alanını, $f_{i}, \theta$ açısından esen rüzgarın esme sıklığını ifade etmektedir.

$P\left(u_{o, i}\right)=\left\{\begin{array}{cl}0 k W, & u_{o, i}<4 \\ \frac{1}{2} \rho A u_{o, i}^{3} C_{p, i} & k W, 4 \leq u_{o, i}<15 \\ 3000 k W, & 15 \leq u_{o, i}<25 \\ 0 k W, & u_{o, i} \geq 25\end{array}\right.$

$P_{t o t}=\sum_{i=1}^{\theta} \sum_{j=1}^{29} P_{j}\left(u_{o, i}\right) f_{i}$

\section{3 $\dot{I} z$ etkisi (Wake) analizi}

Rüzgar santralleri yerleşim problemlerinin çözülmesinde türbinler arası aerodinamik etkileşimden kaynaklanan iz etkisi en önemli kısıttır. İz etkisi, rüzgar santrallerindeki türbinlerin konumlarından dolayı birbirini etkilemesi sonucu rüzgar hızının azalmasını ve enerji üretimindeki azalmayı ifade eder. Rüzgar santrallerinde enerji kayıplarının en büyük nedeni iz etkisinden kaynaklanmaktadır [5].

Santral içindeki her türbin hakim rüzgar yönüne göre konumlandırılmalarına ve birbirlerine göre belirli bir mesafe ile yerleştirilmelerine rağmen, türbinler birbirlerini etkilerler. Öndeki türbine çarpan rüzgar hızı, arkada kalan türbin(ler)e çarpan rüzgar hızına göre daha fazladır. Bu yüzden enerji hesaplamalarında tek bir ortalama rüzgar hızı değeri yerine, her bir türbin için iz etkisinden kaynaklanan yeni rüzgar hızları dikkate alınmalı ve güç hesaplanmaları buna göre yapılmalıdır [6]. 
Şekil 8'de kullanılan momentum korunumu tabanlı iz etkisi modelinin gösterimi verilmiştir [7]. Katic ve arkadaşları [8] tarafından geliştirilen model, uygulama kolaylığı ve düşük hesaplama gereklilikleri nedeniyle rüzgar santrali modellemesinde yaygın bir şekilde benimsenmiştir [9]. $u_{0}$ hızı kesintiye uğramadan türbine çarpan hız olup, $u$ hızı $x_{i, j}$ metre uzaklığındaki hızdır. Bu iz etkisi modeline göre türbine çarpan rüzgarın konik olarak yayılım yaptığı varsayılır ve momentumun korunumu yasası ilkesine göre basınç arttıkça rüzgar hızında düşüş görülür [10]. Oluşan bu konikliğin içine iz bölgesi denmektedir. İz bölgesi rotorun hemen arkasından rotor çap1 büyüklügünde başlar ve genişleyerek büyür. Türbine $u_{0}$ hızı ile çarpan rüzgarın, türbinden $x_{i, j}$ metre sonra ulaştığı $u$ hızının hesaplaması eşitlik (3)’te görülmektedir.

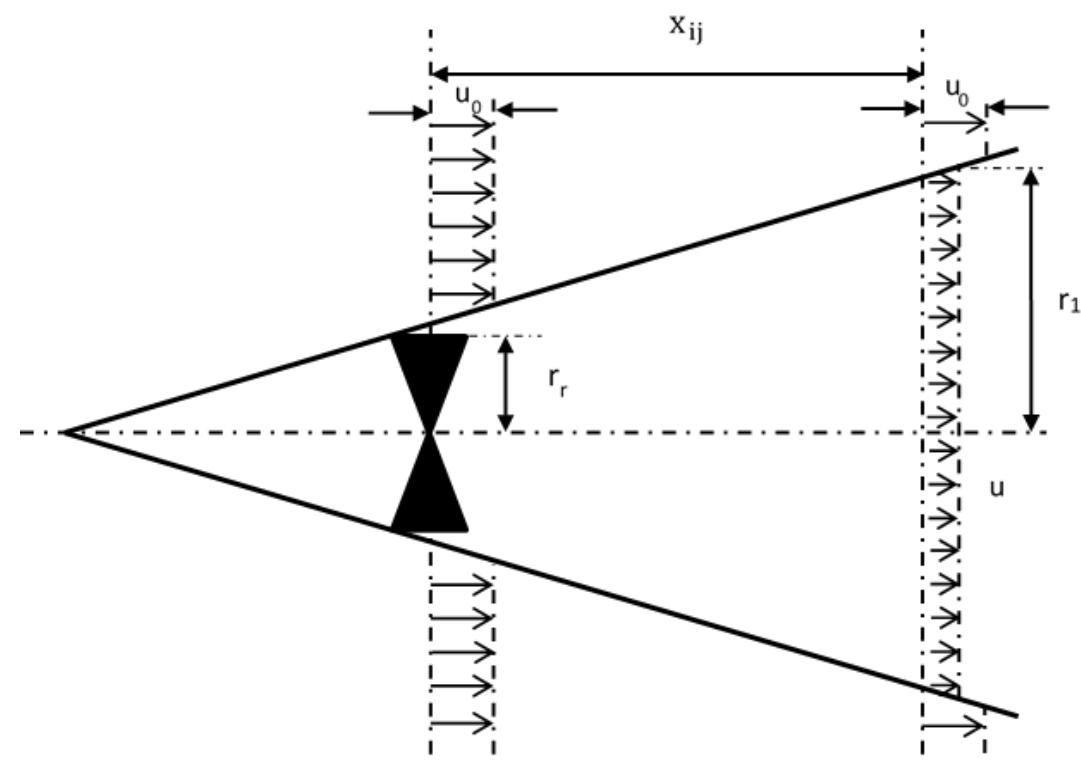

Şekil 8. İz etkisi modelinin şematik gösterimi.

$\mathrm{u}=\mathrm{u}_{0}\left[1-\frac{2 \mathrm{a}}{1+\propto\left(\frac{x_{i, j}}{\mathrm{r}_{r}}\right)}\right]$

Burada; $u_{0}$ ortalama rüzgar hızı, $a$ eksenel indüksiyon faktörü, $x_{i, j}$ türbinin arkasında kalan mesafe, $r_{r}$ türbin arkasında kalan bölgenin yarıçapı, $\alpha$ iz etkisi yayılımını ifade eder ve sürükleme katsayısıdır. (3) eşitliğindeki $a$ eksenel indüksiyon faktörü, serbest akış ile rüzgar türbini arasındaki rüzgar hızının oransal azalmasını ifade eder.

Eşitlik (4) ile (5)'te, türbinin thrust katsayısı $C_{T}$ ile kapasite faktörü $C_{p}$ 'nin eksenel indüksiyon olan $a$ ile olan ilişkisi verilmiştir. Betz teorisine göre maksimum $C_{p}$ değeri 0,59 iken eksenel indüksiyon değeri 1/3 olmaktadır [11].

$\mathrm{C}_{\mathrm{T}}=4 \mathrm{a}(1-\mathrm{a})$

$\mathrm{C}_{\mathrm{P}}=4 \mathrm{a}(1-a)^{2}$

Türbinin arkasında kalan iz bölgesinin yarıçap hesaplaması rotor yarıçapına bağlı olup, (6)'daki gibi ifade edilir. 
$r_{1}=r_{r} \sqrt{\frac{1-a}{1-2 a}}$

$C_{T}$ 'nin hub yüksekliğindeki hıza $\left(u_{h u b}\right)$ bağlı değişimi eşitlik (7)'de ifade edilmiştir [12].

$\mathrm{C}_{\mathrm{T}}=3,5 \times\left(\frac{2 u_{h u b}-3,5}{u_{h u b^{2}}}\right)$

Sürüklenme katsayısı olarak belirtilen $\alpha$ sayısı ampirik olarak şöyle hesaplanır;

$\propto=\frac{0,5}{\ln \left(\frac{\mathrm{z}}{\mathrm{z}_{0}}\right)}$

Eşitlik (8)'de $z$, türbinin hub yüksekliği iken $z_{0}$ ise yüzey pürüzlülüğünü ifade etmektedir. İz etkisinden dolayı azalan hız, türbin sonrasında serbest akış rüzgar hızının kesirli azalması olarak ifade edilir;

vel_def $f_{i j}=1-\frac{u}{u_{0}}=\frac{2 a}{\left(1+\propto \frac{x_{i, j}}{r_{r}}\right)^{2}}$

Eşitlik (9)'da vel_defij, türbin j’nin $\left(R T_{j}\right)$, iz etkisi altında kalan türbin i'nin $\left(R T_{i}\right)$ hızındaki düşüşü tanımlar. $x_{i j}$ ise, $\mathrm{RT}_{\mathrm{i}}$ ile $\mathrm{RT}_{\mathrm{j}}$ arasındaki uzaklıktır ve verilen rüzgar yönü $\theta$ (derece) esas alınarak hesaplanır.

$x_{i, j}=\left|\left(x_{i}-x_{j}\right) \cos \theta+\left(y_{i}-y_{j}\right) \sin \theta\right|$

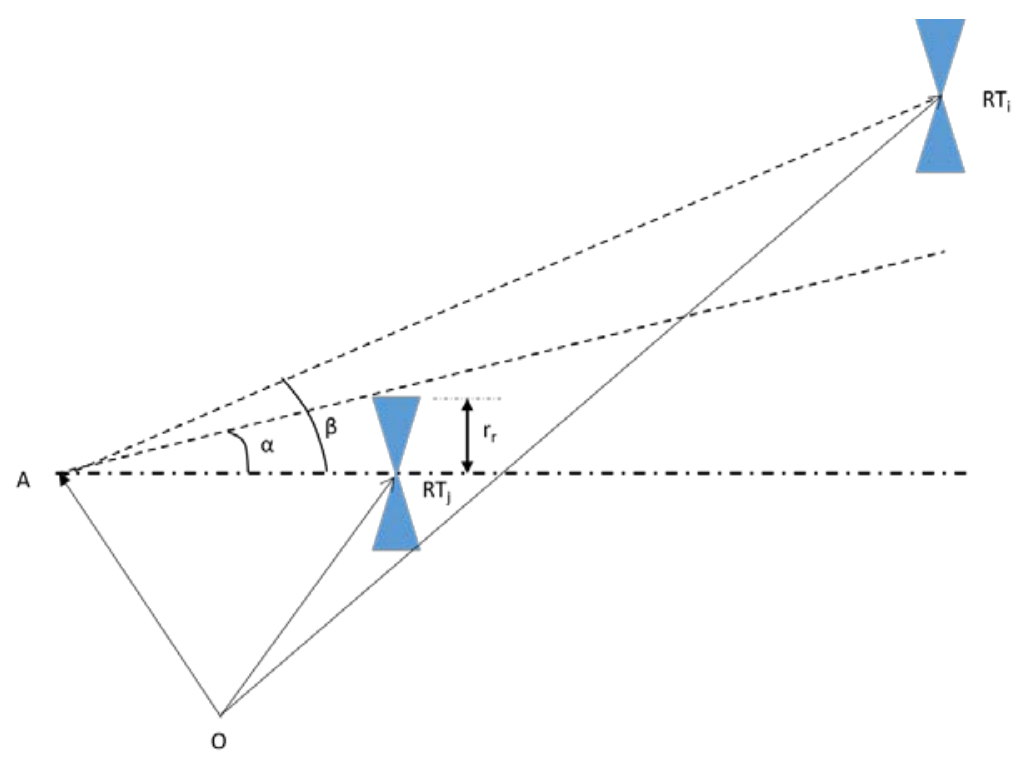

Şekil 9. İz etkisi altında olmayan türbinin belirlenmesi.

Saha içindeki rüzgar türbinlerinin birbirlerini etkilemesi rüzgarın hangi yönden estiğine göre değişir [4]. İz etkisi modeline göre, iz etki alanı konik şeklinde gelişir. Şekil 9, sanal tepe noktası $\mathrm{A}$ olan ve $\mathrm{RT}_{\mathrm{i}}$ ile $\mathrm{RT}_{\mathrm{j}}$ rüzgar türbinleriyle birlikte oluşturduğu yarım koniyi ifade etmektedir. Konikin tepe noktası A ile $\mathrm{RT}_{\mathrm{j}}$ türbininin merkez noktası 
arasındaki mesafe, yani koninin yüksekliği $r_{r} / \propto$ olarak hesaplanır. A noktası ile $\mathrm{RT}_{\mathrm{j}}$ 'nin kanat ucu arasındaki açı olan $\alpha$ açısı ise $\arctan (\propto)$ olarak hesaplanır ve bu açı 0 ile $\pi / 2$ arasında değerler almaktadır. (8)'de eşitliği verilen $\propto$ değeri, iz etki yayılımını ifade etmektedir ve hub yüksekliği ile yeryüzü pürüzlülügüne bağlı olarak değişmektedir. $\mathrm{RT}_{\mathrm{i}}$ ve $\mathrm{RT}_{\mathrm{j}}$ rüzgar türbinlerinin birbirini etkileyip etkilemediği ise $\beta$ açısı hesaplanarak anlaşılabilir ve bu açının değerleri 0 ile $\pi$ arasında değişmektedir. Rüzgarın batı yönünden estiği varsayılan Şekil 9'a göre; $\beta$ açısı $\alpha$ 'dan büyük olduğu için $\mathrm{RT}_{\mathrm{i}}, \mathrm{RT}_{\mathrm{j}}$ 'yi etkilememektedir. $\beta$ açısının $\alpha$ 'dan küçük olması durumunda ise $\mathrm{RT}_{\mathrm{i}}$, $\mathrm{RT}_{\mathrm{j}}$ 'nin iz etkisi altında kalacaktır. Aşağıda verilen (11) denkleminde $\beta$ açısının hesaplaması verilmiştir.

$\beta_{i j}=\cos ^{-1}\left\{\frac{\left(x_{i}-x_{j}\right) \cos \theta+\left(y_{i}-y_{j}\right) \sin \theta+\frac{r_{r}}{\alpha}}{\sqrt{\left(x_{i}-x_{j}+\frac{r_{r}}{\alpha} \cos \theta\right)^{2}+\left(y_{i}-y+\frac{r_{r}}{\alpha} \sin \theta\right)^{2}}}\right\}$

Büyük çaplı rüzgar santrallerinde bir türbin birden fazla türbinin iz etkisinde kalır. Bu durumda $\mathrm{RT}_{\mathrm{j}}$ ve $\mathrm{RT}_{\mathrm{k}}$ etkisinde kalan $\mathrm{RT}_{\mathrm{i}}$ için kümülatif iz etkisi hesaplanır. Birden fazla türbinin gölgelenmesine maruz kalan arkadaki türbinin iz etkisinin gösterimi Şekil 10’da verilmiştir.

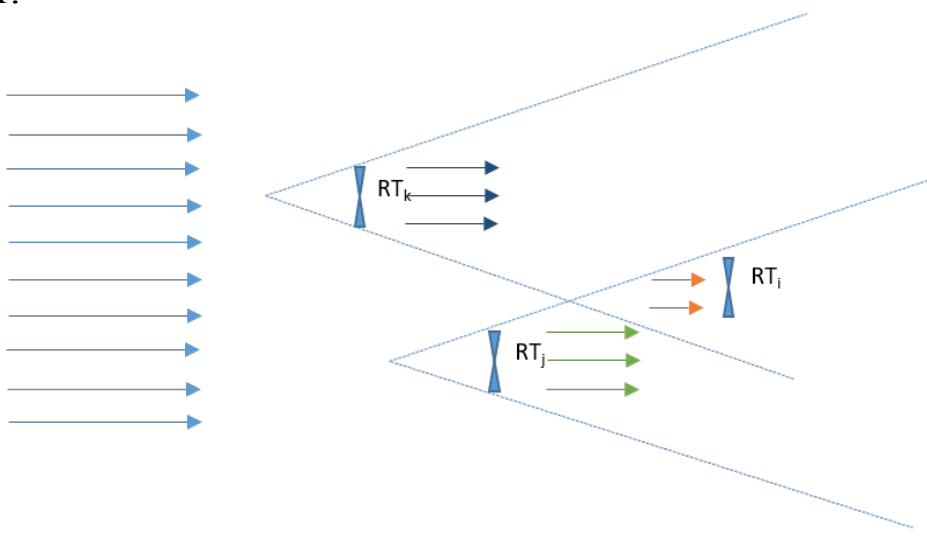

Şekil 10. Çoklu iz etkisi gösterimi.

Bu durumda i. türbinin hızı yani $u_{i}$;

$\mathrm{u}_{\mathrm{i}}=\mathrm{u}_{0}\left(1-\right.$ vel_def $\left.\mathrm{dij}_{\mathrm{j}}\right)$

şeklinde hesaplanırken, birden fazla türbinin iz etkisinde kalan bir türbinin toplam hız kaybı formülü;

vel def $f_{i}=\sqrt{\sum_{j=1, j \neq i, \beta_{i j}<\alpha}^{N} \text { vel_def }_{i, j}^{2}}$

şeklindedir.

\section{Bulgular}

Elektrik satış fiyatının düşük olduğu zamanlar türbinlerin durdurulması, yı1lık rutin bakım ve arızalardan kaynaklı durmalar gibi durumlar dışında türbinlerin aktif olmadığı zamanlar; rüzgar hızının $4 \mathrm{~m} / \mathrm{s}$ 'den az ve $25 \mathrm{~m} / \mathrm{s}$ 'den fazla olduğu zamanlardır. Şekil 
11, sahaya ait rüzgar verilerine dayanarak hazırlanmış rüzgar hızları ile toplam esme süresi arasında oluşturulan histogramı göstermektedir. Taralı olan kısımlar, türbinlerin aktif olarak çalıştığı rüzgar hız aralığını ve bu hızlara karşılık toplam esme saatlerini yani frekansı göstermektedir.

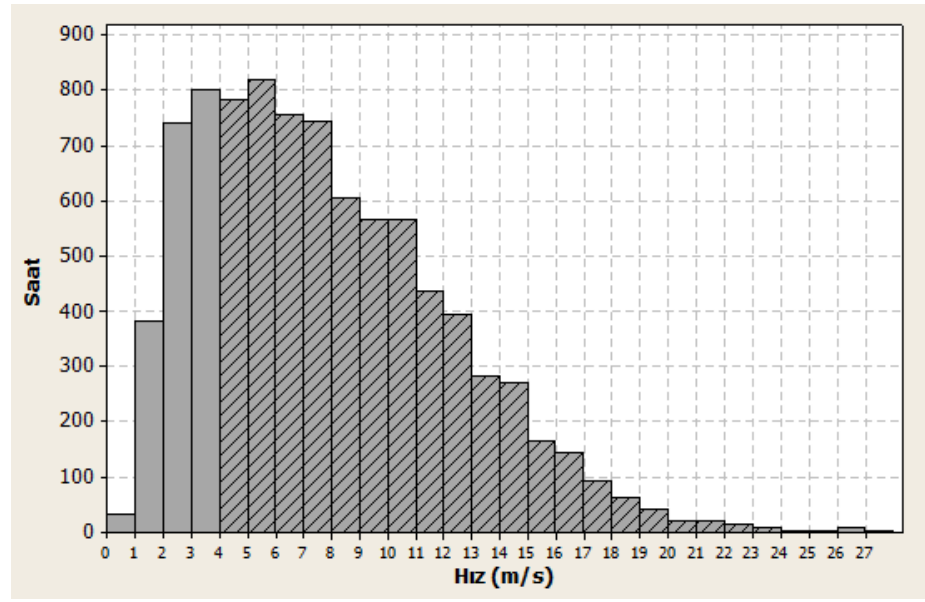

Şekil 11. Türbinlerin aktif çalıştığı süreler ve rüzgar hızı aralığı.

\section{Değerlendirme ve sonuç}

Literatürde yer alan [9,13-15] çalışmalarda olduğu gibi, bu çalışmada da enerji hesaplamalarında 8760 saat esas alınmıştır. Fakat, işletmeden alınan bilgiler doğrultusunda, sahadaki bir türbinin y1lda 2-3 gün (48-72 saat) süren bakım süreleri toplam süreden çıkarılmış, bu yüzden yıllık enerji hesaplamaları 8700 saat kabul edilmiştir.

Varsayımlar doğrultusunda mevcut yerleşim düzeni ile bu çalışmada hesaplanan yıllık enerji üretim değeri karşılaştırıldığında, yapılan hesaplamanın gerçek üretim değerinden \%1,12 kadar daha fazla olduğu görülmektedir. Çalışmada, elektriksel ve mekanik kayıplar dikkate alınmadığından Tablo 2'de RES'ten alınan gerçek veriler ile bu çalışmada hesaplanan enerji üretimlerinin karşılaştırmasını göstermektedir.

Tablo 2. Gerçek veriler ile hesaplanan değerlerin karşılaştırılması.

\begin{tabular}{|c|c|c|}
\cline { 2 - 3 } \multicolumn{1}{c|}{} & $\sum$ Güç Üretimi $(\mathrm{kW})$ & $\sum$ Y1llık Enerji Üretimi $(\mathrm{kWh})$ \\
\hline Gerçek Veriler & $31.689,28$ & $275.696 .736,00$ \\
\hline Hesaplanan Değerler & $32.047,37$ & $278.812 .109,12$ \\
\hline Fark & $1,12 \%$ & $1,12 \%$ \\
\hline
\end{tabular}




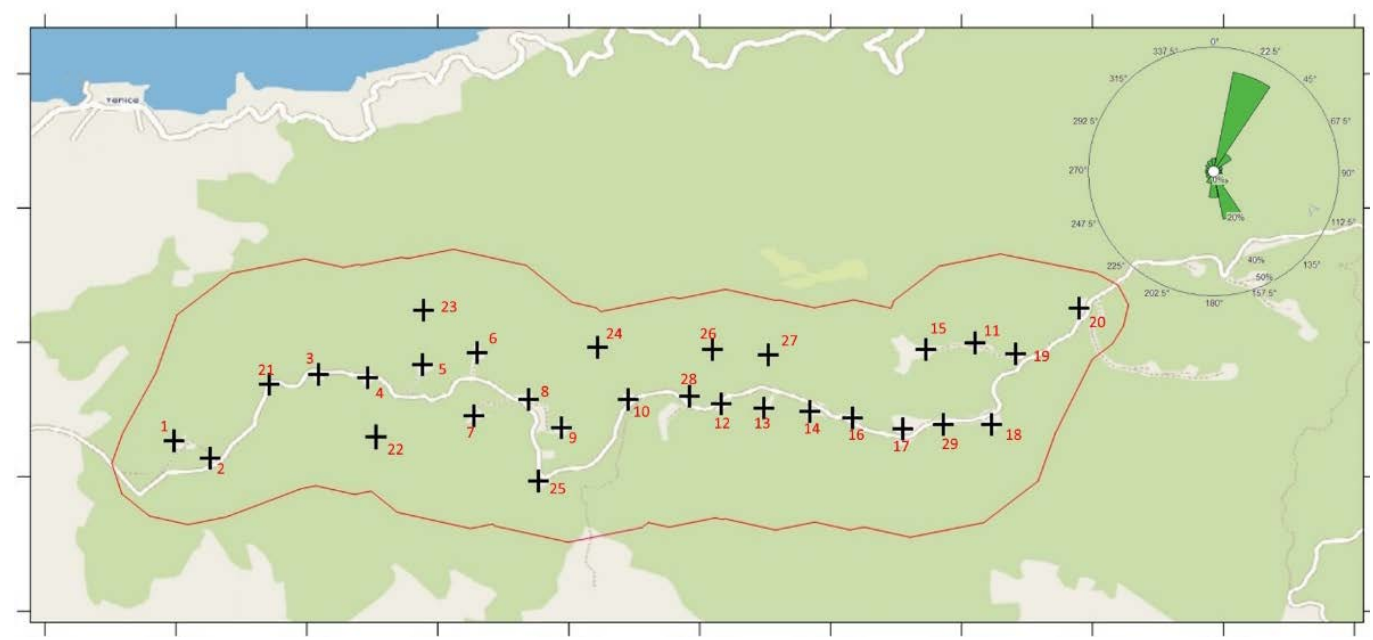

Şekil 12. 29 RT’nin RES sınırları içindeki yerleşimi.

Mevcut durumda en fazla güç üreten türbin ile en az güç üreten türbinlere ait rüzgar hız kayıpları aşağıdaki Tablo 3 'te özetlenmiştir. Yapılan hesaplamalara göre; en fazla güç üreten türbin 1 266,316 kW ile RT11'dir. RT11, hız kayıplarını \%1,69 olasılıkla $67.5^{\circ}$ 'den esen rüzgar sonucunda RT20'den ve $\% 1,12$ ihtimalle $270^{\circ}$ 'den esen rüzgar sonucunda RT15, RT27 ve RT26'dan dolayı yaşamaktadır. Fakat, rüzgarın belirtilen yönlerden esme sıklığı düşük olduğu için RT11; 751,35W'lık kayıpla en fazla güç üreten türbin durumundadır.

En az güç üreten türbin ise 894,517 kW ile RT25’tir. Altı farklı yönden toplamda on altı rüzgar türbininden etkilenmektedir. En fazla hız kaybını \%40,4 olasılıkla 22,5\% yönünden esen rüzgar sonucunda RT09’dan kaybetmektedir.

Tablo 3. En fazla ve en az güç üreten türbinler.

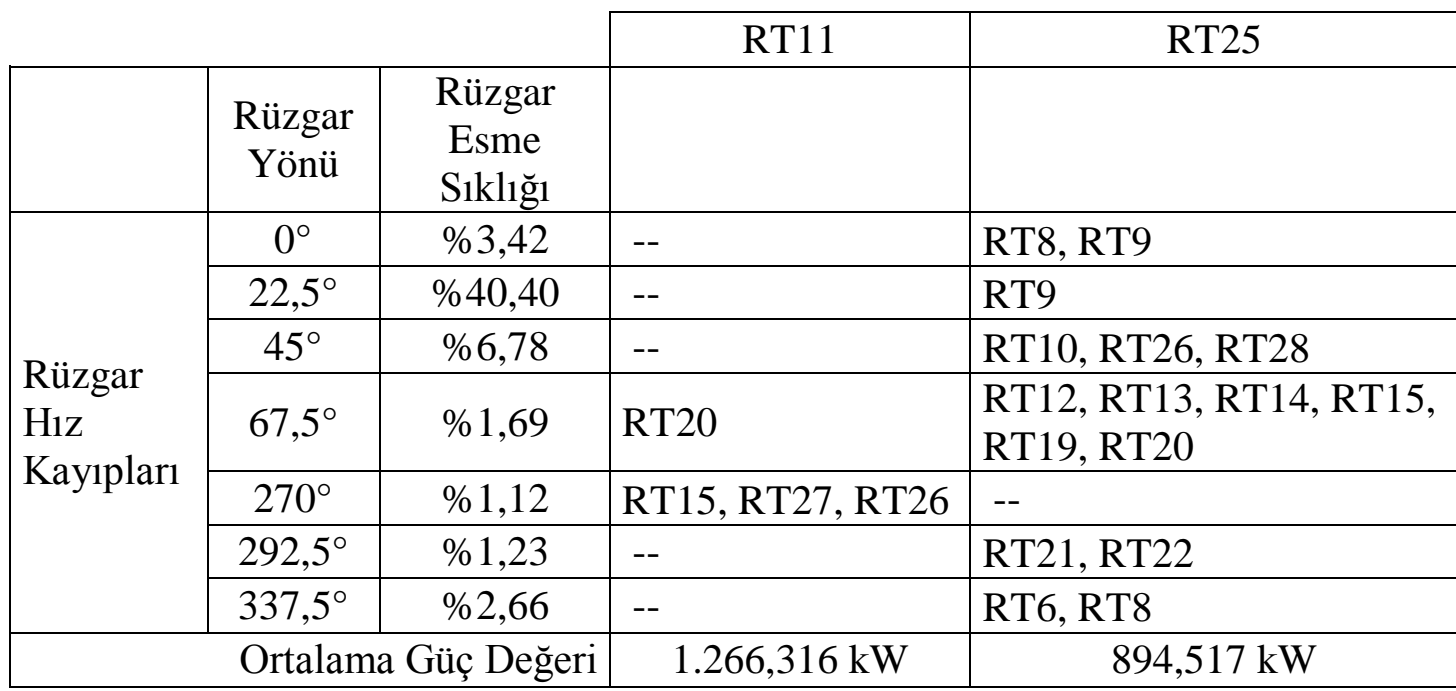

Şekil 13'te ise yapılan hesaplamalardan sonra elde edilen her türbinin, güç kaybı ve ürettikleri güç gösterilmiştir. En fazla güç üreten türbinden en az güç üreten türbine göre sıralanan bu grafikte, en fazla güç kaybı yaşayan RT25 ve RT22, santralde en az güç üreten iki türbindir. En fazla güç üretimi RT11'de görülürken, iz etkisinden 
kaynaklanan hız kaybı yaşamayan RT20 ise en fazla güç üreten üçüncü türbin durumundadir.

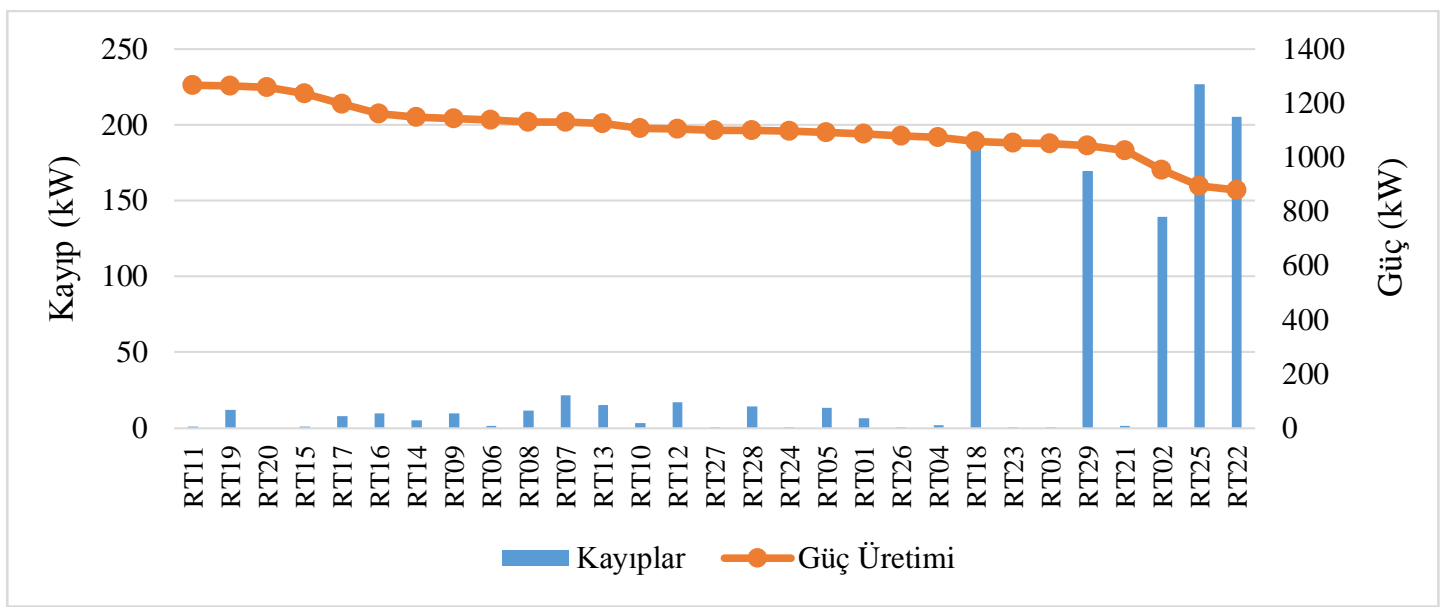

Şekil 13. Rüzgar türbinlerin güç kayıpları ve ürettikleri güç.

$\mathrm{Bu}$ tabloya göre en fazla iz etkisi kaybının yaşandığı rüzgar sektörü 22,5 olup; RT02, RT18, RT22, RT25 ve RT29 türbinlerden toplam 881525,5 W'lık kayıp yaşanmaktadır. Hiç iz etkisi altında kalmayıp güç kaybının yaşanmadığı rüzgar sektörleri 157, $5^{\circ}, 180^{\circ}$ ve $202,5^{\circ}$ 'dir. Tüm rüzgar sektörleri dikkate alındığında ise RT20'de hiçbir iz etkisi kaybının olmadığı görülmektedir.

Sonuç olarak, mevcut düzendeki türbin yerleșimine göre santralde toplam güç üretimi 31.973.903 W ve toplam iz etkisi kaynaklı güç kayb1 1.080.583,54 W bulunmuştur. Tablo 4, santralin mevcut yerleşim düzenine göre yapılan hesaplamaların bir özeti olarak aşağıda verilmiştir.

Tablo 4. Mevcut yerleşim düzenine göre yapılan hesaplamalar özeti.

\begin{tabular}{|l|l|}
\hline Toplam güç üretimi & $31.973,9 \mathrm{~kW}$ \\
\hline İz etkisi kaynaklı güç kaybı & $1.080,584 \mathrm{~kW}$ \\
\hline Max. güç üreten RT & $\mathrm{RT} 11-1.266,316 \mathrm{~kW}$ \\
\hline Min. güç üreten RT & $\mathrm{RT} 25-894,517 \mathrm{~kW}$ \\
\hline En fazla iz etkisi kaybı yaşanan yön & $22,5^{\circ}-881,525 \mathrm{~kW}$ \\
\hline En az iz etkisi kaybı yaşanan yön & $157,5^{\circ}, 180^{\circ}$ ve $202,5^{\circ}-0 \mathrm{~kW}$ \\
\hline İz etkisinde kalmayan türbin & $\mathrm{RT} 20$ \\
\hline En fazla iz etkisi kaybı yaşayan RT & $\mathrm{RT} 25-226,479 \mathrm{~kW}$ \\
\hline En az iz etkisi kaybı yaşayan RT & $\mathrm{RT} 20-0 \mathrm{~kW}$ \\
\hline
\end{tabular}

Sonuç olarak, kurulum ve bakım nedeniyle yüksek giderlere sebep olan rüzgar santrallerinde türbin yerleşim optimizasyonu büyük önem taşımaktadır. Türbinlerin iz etkisi altında olmayışı malzeme yorgunluğunu azaltacak ve beklenen ömürleri içinde çalışmalarını sağlayacaktır [9]. RES’lerdeki türbinlerin birbiri ile etkileşimini yani iz etkisini en aza indirerek, türbinlerin maksimum gücü üretmelerini sağlayan optimal bir yerleşim düzeni, üzerinde çalışma yapılması gereken önemli konulardan birisidir. Çünkü, bir RES’in yerleşim düzeninin toplam gücü artırma ve türbinler üzerinde yapısal yükleri azaltma potansiyeli vardır. 


\section{Kaynaklar}

[1] Şenel M., Yatay Eksenli Rüzgar Türbinlerindeki Aerodinamik, Mekanik ve Elektriksel Kayıpların Değerlendirilmesi, Rüzgar Enerjisi Dergisi, 56-62, (2015).

[2] Torres P, Van Wingerden JW, Verhaegen M., Modeling of the flow in wind farms for total power optimization, IEEE International Conference on Control and Automation, ICCA, 963-968, (2011).

[3] Karasu Asnaz M.S., Popülasyon temelli sezgisel algoritmaya dayanan genetik algoritma ile rüzgar santrali türbin yerleşimi optimizasyonu ve bir uygulama. Doktora Tezi, Balıkesir Üniversitesi, Fen Bilimleri Enstitüsü, Balıkesir, (2017).

[4] Kusiak A, Song Z., Design of wind farm layout for maximum wind energy capture, Renewable Energy, 35, 685-694, (2010).

[5] Diamond, Kimberly; Crivella E., Wind Turbine Wakes, Wake Effect Impacts, And Wind Leases: Using Solar Access Laws As The Model For Capitalizing On Wind Rights During The Evolution Of Wind Policy Standards, 195-244, (2011).

[6] Tesauro P., State of the Art of Wind Farm Optimization, Proceedings of EWEA 2012 - European Wind Energy Conference \& Exhibition, 1-11,(2012).

[7] Grady S., Hussaini M.Y, Abdullah M.M., Placement of wind turbines using genetic algorithms. Renewable Energy, 30, 259-270, (2005).

[8] Katic, I., Hojstrup, J., Jensen N.O., A simple model for cluster efficiency i.katic. j.højstrup. n.o.jensen, Ewea 1986, 407-410, (1986).

[9] Serrano González J, Burgos Payán M, Santos JMR, González-Longatt F., A review and recent developments in the optimal wind-turbine micro-siting problem. Renewable and Sustainable Energy Reviews,30, 133-144, (2014).

[10] Eroğlu Y. Wind Farm Layout Optimization using Ant Colony and Particle Filtering Approaches, Yüksek Lisans Tezi, Gaziantep Üniversitesi, Fen Bilimleri Enstitüsü, Gaziantep, (2011).

[11] Manwell, J.F.; McGowan J.G.; Rogers A.L., Wind Energy Explained - Theory, Design, and Application, Wiley, (2002).

[12] Frohboese P., Schmuck C., Hassan G.L.G., Thrust Coefficients Used for Estimation of Wake Effects for Fatigue Load Calculation, European Wind Energy Conference 2010, 1-10, (2010).

[13] Mustakerov I., Borissova D. Wind turbines type and number choice using combinatorial optimization, Renewable Energy, 35, 1887-1894, (2010).

[14] Elkinton C.N., Offshore Wind Farm Layout Optimization. Yüksek Lisans Tezi, University of Massachusetts, Amherst, (2007).

[15] Rašuo B., Bengin A., Optimization of wind farm layout, FME Transactions, 38, 107-114, (2010). 